\title{
Análise da viabilidade do uso de resíduos de cana-de-açúcar para produção de aglomerantes sustentáveis
}

\author{
Analysis of the influence of calcination \\ temperature of sugarcane residues \\ for the production of binders
}

Mateus Arlindo da $\mathrm{Cruz}^{1}$, Rafaela Fontana Casanova ${ }^{1}$, Daiane Boscardin ${ }^{1}$, Aline Zanchet ${ }^{1}$

\footnotetext{
${ }^{1}$ Faculdade Meridional- IMED, Departamento de Engenharia Civil. Rua Gen. Prestes Guimarães, 304, Vila Rodrigues, CEP: 99070-220, Passo Fundo, RS, Brasil.

e-mail: mateusArlindo@hotmail.com,rafaelafcasanova@hotmail.com, daiane_boscardin@outlook.com,

aline.zanchet@gmail.com
}

\begin{abstract}
RESUMO
A cinza de bagaço de cana-de-açúcar é um subproduto oriundo do processo de cogeração de energia elétrica. Este resíduo é composto principalmente por sílica, desta forma, podendo ser reutilizado como agregado e/ou como aglomerante em matrizes cimentícias. O presente trabalho tem como objetivo principal analisar as propriedades físico-químicas da cinza do bagaço de cana-de-açúcar, quando calcinada em diferentes temperaturas, visando a sua aplicação como aglomerante em uma matriz sustentável. O resíduo (bagaço de cana-de-açúcar) utilizado na presente pesquisa, foi coletado no município de Porto Xavier, localizado no estado do Rio Grande do Sul. Para a análise, o resíduo foi separado em quatro amostras e então calcinado em uma mufla com temperatura controlada, sendo respectivamente: $500^{\circ} \mathrm{C}, 600^{\circ} \mathrm{C}, 700^{\circ} \mathrm{C}$ e $800^{\circ} \mathrm{C}$, por um período de uma hora. $\mathrm{O}$ processo de calcinação do resíduo tem como finalidade a remoção da matéria orgânica presente. Para a análise das propriedades físico-químicas das amostras, utilizou-se as técnicas de Difração de Raio-X (DRX), Análise Termogravimétrica (TGA), reatividade pozolânica e Microscopia Eletrônica de Varredura (MEV). Os resultados indicam um maior grau de amorfismo na amostra calcinada a $500{ }^{\circ} \mathrm{C}$ e maior grau de cristalinidade em $800^{\circ} \mathrm{C}$. Se mostrando um material com ótimas características para o uso na produção de aglomerantes sustentáveis.

Palavras-chave: Bagaço da cana-de-açúcar; Temperatura de calcinação; Reatividade Pozolânica; Estrutura físico-química.
\end{abstract}

\begin{abstract}
Sugarcane bagasse ash is a by-product from the electricity cogeneration process. This residue is mainly composed of silica, so it can be reused as an aggregate and / or as a binder in cementitious matrices. The present work has as main objective to analyze the physicochemical properties of the sugarcane bagasse ash, when calcined at different temperatures, aiming at its application as a binder in a sustainable matrix. The residue (sugarcane bagasse) used in the present study was collected in the municipality of Porto Xavier, located in the state of Rio Grande do Sul. For the analysis, the residue was separated into four samples and then calcined in a muffle with controlled temperature, respectively: $500^{\circ} \mathrm{C}, 600^{\circ} \mathrm{C}, 700^{\circ} \mathrm{C}$ and $800^{\circ} \mathrm{C}$, for a period of one hour. The residue calcination process aims to remove the organic matter present. For the analysis of the physical-chemical properties of the samples, the techniques of X-Ray Diffraction (XRD), Thermogravimetric Analysis (TGA), pozzolanic reactivity and Scanning Electron Microscopy (SEM) were used. The results indicate a higher degree of amorphism in the sample calcined at $500^{\circ} \mathrm{C}$ and a greater degree of crystallinity at $800^{\circ} \mathrm{C}$. Showing a material with great characteristics for use in the production of sustainable binders.
\end{abstract}

Keywords: Sugarcane bagasse; Calcination temperature; Pozzolanic Reactivity; Physicochemical structure.

\section{INTRODUÇÃO}

O concreto produzido com cimento Portland se destaca por ser o principal material e o mais utilizado em canteiro de obras em todo o mundo. Nas grandes construções da antiguidade, já se encontrava misturas 
compostas por água, agregados e materiais aglomerantes nas estruturas. Esta mistura entre aglomerado e aglomerante combinavam de tal forma, que mesmo após séculos, algumas construções ainda resistem as ações das intempéries. A resistência mecânica aliada com a versatilidade, rapidez e o baixo custo, fazem com que a aplicação do concreto seja ampla, podendo abranger tanto construções de pequeno porte (casa, edificação residencial, entre outras), como também, construções mais robustas (viadutos, barragens e túneis) [13].

Em 2017 a produção de cimento Portland mundialmente alcançou 4,2 bilhões de toneladas/ano [11]. Em virtude desta demanda, preocupações com as questões referentes a sustentabilidade se fazem presentes.

A preocupação com o meio ambiente e com a sustentabilidade tem levado o setor da construção civil a realizar grandes mudanças em seus processos produtivos e construtivos, devido ao grande impacto que suas obras causam para o meio ambiente [29]. Algumas práticas da sociedade vêm contribuindo para esta mudança de hábitos no setor, visto que, cada vez mais os consumidores buscam empresas e produtos que possuem certificação ambiental, responsabilidade social e ética.

Dentro deste contexto, estudos visando a redução da produção de clínquer ou até mesmo buscando alternativas para substituição parcial e/ou total deste produto, atrelados a uma melhor durabilidade e resistência, vem se intensificando nos últimos anos $[\underline{4}, \underline{10}, \underline{13}, \underline{16}, \underline{22}]$.

As cinzas volantes são consideradas materiais promissores para a produção de materiais geopoliméricos ou matrizes cimentícias, devido aos benefícios ambientais, já que as mesmas são resultado de um processo de produção de eletricidade por meio da calcinação do carvão mineral, sendo considerados subprodutos das empresas [26]. Na mesma classe das cinzas volantes encontra-se as cinzas de bagaço de cana-de-açúcar (CBC). A CBC, é oriunda de um processo de queima do bagaço de cana utilizado para geração de energia. Cerca de $10 \%$ do total do bagaço queimado se torna cinzas [21, $\underline{5}$ ]. Devido as características químicas e físicas, este material vem sendo estudo para utilização em matrizes cimentícias. De acordo com [27], a utilização da cinza de bagaço de cana-de-açúcar (CBC), é sem dúvida uma forma de cooperar com a preservação do meio ambiente e dando a esta uma destinação correta, reduzindo as deposições das cinzas em locais impróprios na natureza [19]

De acordo com Cioffi é possível produzir materiais ativados alcalinamente através de resíduos e matérias primas já calcinadas [12]. Ainda segundo os autores supracitados, as propriedades mecânicas e físicas dos compósitos podem ser melhoradas através de um processo de calcinação controlado.

Neste contexto este estudo se justifica pela importância de analisar e entender as vantagens ocasionadas na utilização de um resíduo produzido em grande escala no país (cinza do bagaço de cana-de-açúcar), visando uma diminuição da emissão de gases poluentes e oferecendo uma melhor finalidade para o resíduo, desta forma, buscando promover vantagens ambientais por meio de uma destinação ecologicamente correta. A presente pesquisa se propõe a verificar qual a influência da temperatura de calcinação nas propriedades físico-química da cinza do bagaço de cana-de-açúcar, bem como, inferir qual a melhor temperatura de calcinação do resíduo.

\section{REFERENCIAL TEÓRICO}

\subsection{Cana-de-açúcar}

A cana-de-açúcar é uma gramínea, originalmente cultivada na Ásia e na Índia, ela foi implementada no Brasil ainda no período de colonização, nos meados do século XVI [30]. A cana-de-açúcar logo se tornou de fundamental importância para a economia brasileira, devido a sua rápida adaptação ao clima tropical e a sua versatilidade, visto que a mesma pode ser utilizada tanto na forma mais simples (ração para animais), quanto na forma mais refinada [24].

A cana-de-açúcar é uma das espécies mais cultivadas em todo o mundo. Ela é cultivada em mais de 100 países, sendo o Brasil e a Índia os maiores produtores mundiais [17, 19]. Quando comparado apenas a produção agrícola brasileira, é possível notar que a cana-de-açúcar se destaca mais uma vez, sendo a terceira espécie mais cultivada no país em relação a área colhida sendo a cultura que tem maior produção em toneladas e a que possui maior produtividade por hectare dentre as sete culturas mais cultivadas no país [24].

Toda a produção da agroindústria da cana-de-açúcar, acaba gerando uma quantidade extremamente grande de resíduos sólidos, e ainda resíduos líquidos, provenientes do processo de lavagem da cana-de-açúcar do longo da cadeia de produção. 


\subsection{Resíduos de cana-de-açúcar}

Cerca de $69 \%$ de todos os resíduos produzidos pela agroindústria, vem da produção da cana-de-açúcar [7]. A cada mil quilos de cana-de-açúcar utilizada para a produção de álcool, são gerados $280 \mathrm{~kg}$ de bagaço e palha da cana como resíduos. A cultura da cana-de-açúcar ao longo dos anos já causou um enorme dano ao meio ambiente, visto que os resíduos eram despejados sem nenhum tipo de controle principalmente em rios [23].

Com o aumento da produção agrícola da cana-de-açúcar, ocorre o aumento dos resíduos gerados por ela. Estes resíduos podem ser prejudiciais ao meio ambiente, obrigando governos e demais entidades a buscarem a criação de leis e normatizações para o tratamento destes resíduos. No Brasil destaca-se a NBR 10004/2004, que dispõem sobre o tratamento dos resíduos sólidos. Esta norma trata de todo os resíduos sólidos, ou semissólidos proveniente da atividade agrícola, industrial, doméstica entre outros [1].

A NBR 10004/2004 classifica os resíduos sólidos em 3 classes distintas, sendo que a classe I os resíduos perigosos, classe II A os não inertes e classe II B os inertes. Dentre os principais resíduos sólidos do processamento da cana-de-açúcar destaca-se o bagaço, a palha, a vinhaça, as cinzas das caldeiras dentre outros $[\underline{1}, \underline{20}]$.

O bagaço de cana-de-açúcar, possui uma umidade média de aproximadamente $50 \%$ e poder calorífico de $2.275 \mathrm{kcal} / \mathrm{kg}$, sendo que em alguns casos este valor pode chegar a $4.360 \mathrm{kcal} / \mathrm{kg}$ em condições de umidade $0 \%[\underline{31}]$.

\section{MATERIAIS E MÉTODOS}

\subsection{Resíduos de cana-de-açúcar}

O resíduo utilizado na caracterização foi a cinza de bagaço de cana-de-açúcar calcinada em diferentes temperaturas. O bagaço da cana-de-açúcar foi coletado na cooperativa dos produtores de cana-de-açúcar de Porto Xavier - Coopercana, localizado na cidade de Porto Xavier, estado do Rio Grande do Sul. Para a realização dos ensaios elencados no presente trabalho, foram coletados aproximadamente 200 quilos de bagaço de cana-de-açúcar in natura, conforme demonstra a Figura 01.

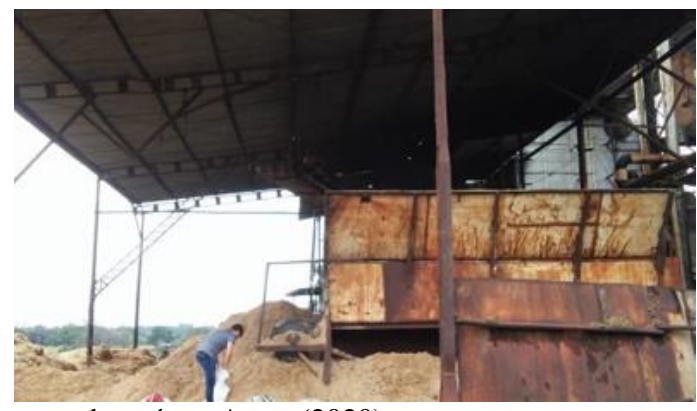

Figura 1: Coleta dos resíduos de cana-de-açúcar. Autor (2020).

Após a coleta dos resíduos de cana-de-açúcar realizou-se a calcinação em diferentes temperaturas $\left(500^{\circ} \mathrm{C}, 600^{\circ} \mathrm{C}, 700^{\circ} \mathrm{C}\right.$ e $\left.800^{\circ} \mathrm{C}\right)$. Para o processo foi utilizado um forno mufla com capacidade de atingir até $1200^{\circ} \mathrm{C}$, no laboratório de materiais e pavimentação da Faculdade Meridional - IMED, campus de Passo Fundo.

Os resíduos foram colocados em um recipiente refratário, no qual foram aquecidos até chegar na temperatura de calcinação desejada, após isso os mesmos ficaram sob a temperatura de calcinação constante durante o período de 1 hora. Passado o período de calcinação na temperatura constante, os resíduos foram retirados da mufla e resfriados em temperatura ambiente [18]. Após esse período de calcinação os resíduos sofreram o processo de resfriamento.

$\mathrm{O}$ processo de resfriamento foi realizado de forma controlada, na faixa de $10^{\circ} \mathrm{C} / \mathrm{min}$ para todas as temperaturas de calcinação realizadas, conforme metodologia utilizada e recomendada por [10]. Após o fim do processo de resfriamento, foi possível obter as cinzas de resíduos de cana-de-açúcar para as diferentes temperaturas, conforme demonstra a Figura 02. 


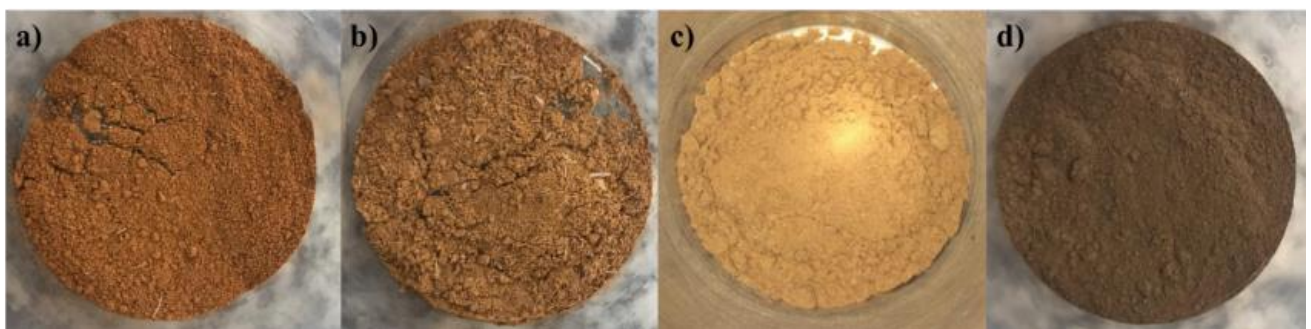

Figura 2: Cinzas de resíduos de cana-de-açúcar calcinadas onde $\mathrm{a}=500^{\circ} \mathrm{C}, \mathrm{b}=600^{\circ} \mathrm{C}, \mathrm{c}=700^{\circ} \mathrm{C}$ e d $=800^{\circ} \mathrm{C}$. Autor (2020).

\subsection{Análises termogravimétrica}

A análise termogravimétrica (TGA), foi realizada na Universidade de Caxias do Sul - UCS, na cidade de Caxias do Sul, estado do Rio Grande do Sul, com a finalidade de determinar a perda de massa em função da temperatura dos resíduos calcinados a diferentes temperaturas $\left(500^{\circ} \mathrm{C}, 600^{\circ} \mathrm{C}, 700^{\circ} \mathrm{C}\right.$ e $\left.800^{\circ} \mathrm{C}\right)$. As análises foram realizadas em um analisador termogravimétrico Shimadzu - modelo TGA-50. A taxa de aquecimento utilizada nos testes foi de $10^{\circ} \mathrm{C}$.min-1, sob fluxo de $50 \mathrm{~mL}$ min-1 de nitrogênio, na faixa de temperatura entre 20 e $900^{\circ} \mathrm{C}$.

\subsection{Reatividade pozolânica}

A reatividade pozolânica das cinzas oriundas de diferentes temperaturas de calcinação $\left(500^{\circ} \mathrm{C}, 600^{\circ} \mathrm{C}, 700^{\circ} \mathrm{C}\right.$ e $800^{\circ} \mathrm{C}$ ), foram determinadas com base na NBR 15895:2010 [3] , pelo método de Chapelle modificado. $\mathrm{O}$ ensaio teve por finalidade avaliar qual das cinzas tinha maior reatividade pozolânica, sendo este um parâmetro essencial para substâncias que visam ser constituintes de materiais cimentantes.

A pozolanicidade das cinzas dos resíduos de cana-de-açúcar fora determinada com base na capacidade do material de fixar hidróxido de cálcio quando mantido em uma solução aquosa com óxido de cálcio. De forma simplificada, o método consiste em manter em aquecimento sob $90{ }^{\circ} \mathrm{C}$ em banho maria, durante no mínimo 16 horas uma solução com $1,000 \mathrm{~g}$ de óxido de cálcio, 1,000 g de cinza e 250,00 g de água isenta de dióxido de carbono.

Ao final do ensaio, o teor de $\mathrm{CaO}$ livre é medido, por meio de titulação de cerca de $50 \mathrm{~mL}$ da solução com $\mathrm{HCl}$ utilizando fenolftaleína $(1 \mathrm{~g} / \mathrm{L})$, e estima-se a quantidade de $\mathrm{CaO}$ que foi combinada com as cinzas. O resultado é expresso pela quantidade de óxido de cálcio fixado por grama de cinza e estimado a reatividade pozolânica do material.

O índice mínimo de consumo de $\mathrm{Ca}(\mathrm{OH})_{2}$ para um material pozolânico deve ser de $300 \mathrm{mg} / \mathrm{g}$ utilizando o método de Chapelle modificado [28]. O ensaio foi realizado no laboratório de química do curso de Engenharia Civil da Faculdade Meridional - IMED, campus de Passo Fundo.

\subsection{Difração de raio-X}

Esta técnica foi utilizada para determinar as fases cristalinas e amorfas do precursor. A difração de raio-X (DRX), baseia-se no método de difração Fraunhoffe, que afirma que quanto menor for a partícula analisada, maior será o ângulo de difração de um feixe luminoso que travessará uma união de partículas.

O ensaio foi realizado no laboratório de materiais do curso de engenharia química da Universidade Federal de Santa Maria - UFSM, localizada na cidade de Santa Maria, estado do Rio Grande do Sul nas amostras calcinadas a $500^{\circ} \mathrm{C}, 600^{\circ} \mathrm{C}, 700^{\circ} \mathrm{C}$ e $800^{\circ} \mathrm{C}$. O equipamento utilizado no ensaio foi um difratômetro de raios X Rigaku, modelo Miniflex ${ }^{\circledR} 300$, no qual possui radiação de $\mathrm{Cu} \operatorname{Ka}(\lambda=1,54051 \AA)$ e fonte de energia com $30 \mathrm{kV}$ e $10 \mathrm{~mA}$, permitindo aquisição de difratogramas com ângulos entre 5 e $100^{\circ}$.

O método utilizado no ensaio foi o de modo Step, com Scan speed de $0,5 \mathrm{~s}$ e Scan step de $0,03^{\circ}$. As amostras enviadas para análise foram peneiradas em peneira com mesh de $60 \mathrm{~mm}$ na porção de aproximadamente $1 \mathrm{~g}$.

\subsection{Microscopia eletrônica de varredura}

Os ensaios de microscopia eletrônica de varredura (MEV), foram realizados com a finalidade de se estudar a morfologia e a superfície do resíduo, bem como serão avaliadas as estruturas do geopolímero após a moldagem dos corpos de prova. As microscopias eletrônicas de varredura foram realizadas no laboratório de materiais da Universidade Estadual Paulista - UNESP, campus de Guaratinguetá. 


\section{RESULTADOS}

\subsection{Análises termogravimétrica}

A análise das CBC calcinadas em diferentes temperaturas por meio da análise termogravimétrica (TGA), serviu para determinar a transformação ou decomposição desses materiais quando submetidos a elevadas temperaturas. A Figura 03, apresenta os dados de perda de massa das $\mathrm{CBC}$ calcinada a temperatura de $500^{\circ} \mathrm{C}$, juntamente com a sua derivada, quando submetidas ao ensaio de TGA, seguindo os parâmetros citados na metodologia do presente trabalho.

Através na análise da Figura 03 é possível notar que houve uma perda de massa na temperatura de aproximadamente $144^{\circ} \mathrm{C}$, esta perda diz respeito a decomposição da água intracelular na amostra. A segunda perda de massa da amostra ocorreu na temperatura de $267^{\circ} \mathrm{C}$ que diz respeito a decomposição da celulose presente na amostra. Os resíduos de cana-de-açúcar contêm em sua composição óxidos não voláteis que quando atingem temperaturas acima de $600^{\circ} \mathrm{C}$ começam a oxidar, gerando ganho de massa da amostra. Ainda se ressalta os dados de perda de massa condizem com os resultados da literatura $[\underline{6}, \underline{10}]$.

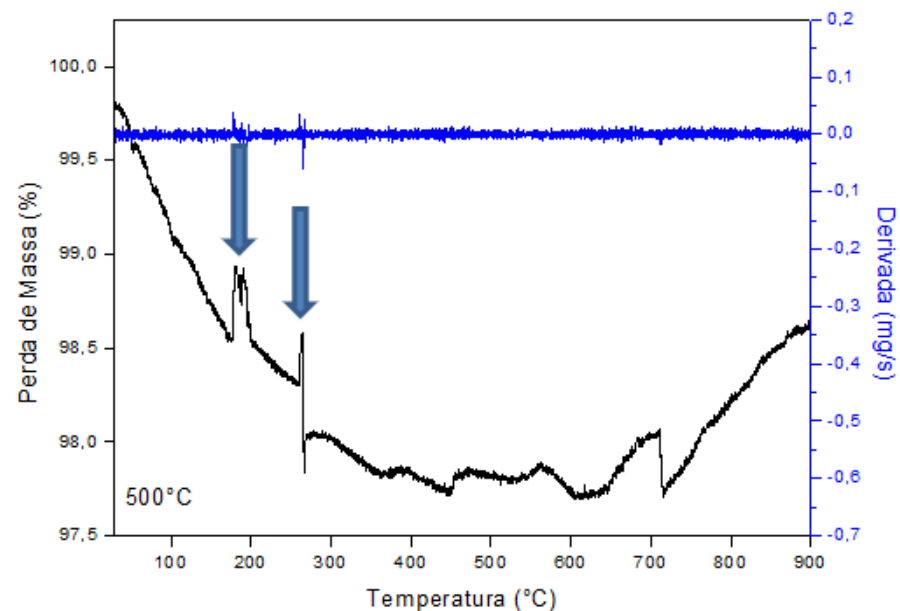

Figura 3: Curvas TG e derivada para $\mathrm{CBC} 500^{\circ} \mathrm{C}$. Autor (2020).

$\mathrm{Na}$ Figura 04 é apresentada as curvas TG e derivada para a $\mathrm{CBC}$ calcinada na temperatura de $600^{\circ} \mathrm{C}$. Ao analisar a mesma é possível observar a perda de massa decorrente da decomposição da água intracelular e da celulose nas temperaturas de $112^{\circ} \mathrm{C}$ e $250^{\circ} \mathrm{C}$ respectivamente.

Ainda é possível notar uma perda de massa na temperatura de $390^{\circ} \mathrm{C}$, está perda de massa diz respeito a decomposição da lignina presente na amostra. A partir da temperatura de $640^{\circ} \mathrm{C}$ ocorre a decomposição de óxidos presente na amostra, gerando oxidações e consequentemente ganho de massa na amostra.

$\mathrm{O}$ mesmo comportamento de ganho de massa que ocorre acima de $600^{\circ} \mathrm{C}$, foi encontrado na cinza calcinada em $500^{\circ} \mathrm{C}$ (Fig 03)



Figura 4: Curvas TG e derivada para $\mathrm{CBC} 600^{\circ} \mathrm{C}$. Autor (2020). 
Ainda a partir da temperatura de calcinação de $700^{\circ} \mathrm{C}$, observa-se que as $\mathrm{CBC}$ não obtiveram perda de massa, e sim um ganho de massa, conforme demonstram as Figuras 05 e 06. Este resultado pode ser justificado pela oxidação do ferro (Fe) presente nas amostras do material [13]. Segundo [31], os óxidos de ferro se transformam em Goethita, Hematita e Magnetita nas temperaturas de $450^{\circ} \mathrm{C}, 700^{\circ} \mathrm{C}$ e $900^{\circ} \mathrm{C}$ respectivamente, com a degradação da matéria orgânica pela temperatura de calcinação, o oxigênio tem seu acesso favorecido na superfície destes óxidos. Este fenômeno provoca um ganho de massa na amostra.

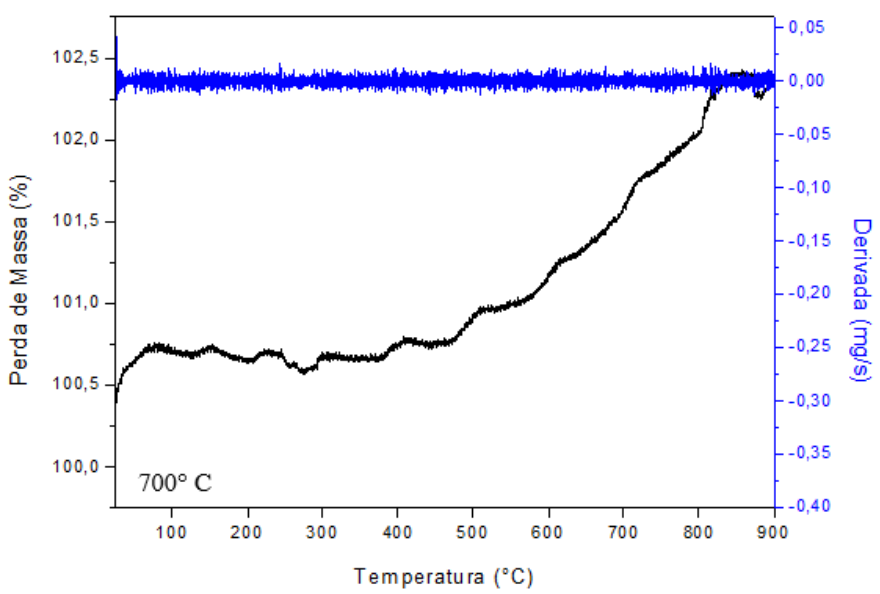

Figura 5: Curvas $\mathrm{TG}$ e derivada para $\mathrm{CBC} 700^{\circ} \mathrm{C}$. Autor (2020).

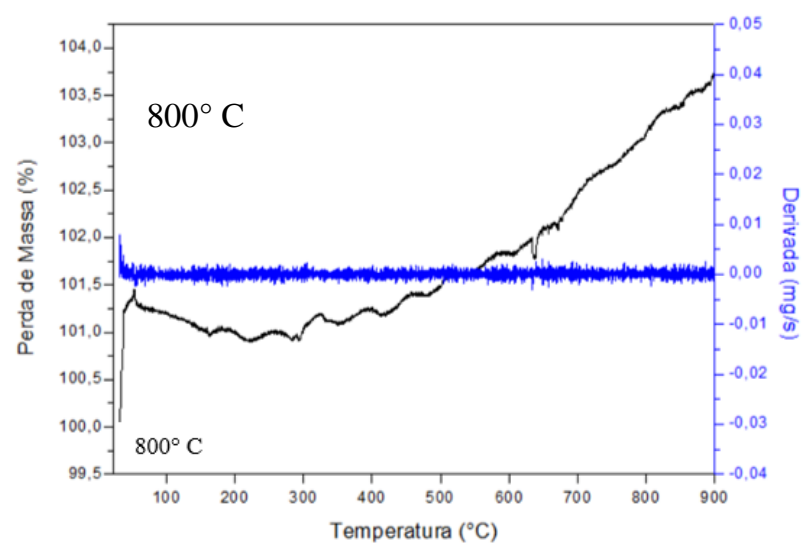

Figura 6: Curvas TG e derivada para $\mathrm{CBC} 800^{\circ} \mathrm{C}$. Autor (2020).

A Tabela 01 apresenta os dados de perda de massa de cada CBC produzida em diferentes temperaturas de calcinação. Nela é possível observar que quanto maior a temperatura de calcinação dos resíduos das CBC, menor será a perda de massa do material quando submetido a altas temperaturas. Conforme podemos observar na Tabela 01, os resultados obtidos na presente pesquisa se demonstraram similares aos dados obtidos por Cordeiro [13], outro ponto a se observar é que em todas as temperaturas de calcinação as CBC's atenderam aos requisitos da NBR 12653 [2] no aspecto de perda de massa.

Tabela 1: Perda de massa das CBC.

\begin{tabular}{c|c}
\hline Temperatura de calcinação das CBC & Perda de massa (\%) \\
\hline $500^{\circ} \mathrm{C}$ & 2,297 \\
\hline $600^{\circ} \mathrm{C}$ & 1,086 \\
\hline $700^{\circ} \mathrm{C}$ & $-2,390$ \\
\hline $800^{\circ} \mathrm{C}$ & $-3,695$ \\
\hline
\end{tabular}




\subsection{Reatividade pozolânica}

A reatividade pozolânica das $\mathrm{CBC}$ calcinadas em diferentes temperaturas foi definida pelo método de Chapelle modificado conforme metodologia supracitada, a fim de determinar qual das CBC possui maior atividade pozolânica e consequente maior poder de reação pozolânica quando utilizado para a produção do geopolímero. A Tabela 02 apresenta os índices de atividade pozolânica das CBC obtidos de diferentes temperaturas pelo método de Chapelle modificado.

Tabela 2: Índice de atividade pozolânica

\begin{tabular}{cc}
\hline Temperatura de calcinação das CBC & $\mathbf{I ~ C a}(\mathbf{O H})_{\mathbf{2}} \mathbf{( \mathbf { m g } / \mathbf { g } )}$ \\
\hline $500^{\circ} \mathrm{C}$ & 321,86 \\
$600^{\circ} \mathrm{C}$ & 339,37 \\
$700^{\circ} \mathrm{C}$ & 359,08 \\
$800^{\circ} \mathrm{C}$ & 367,84 \\
\hline
\end{tabular}

Ao analisar a Tabela 02 é possível definir que conforme a temperatura de calcinação das CBC's é elevada maior será o índice de atividade pozolânica pelo método de Chapelle modificado. Os valores da atividade pozolânica obtidos na presente pesquisa são condizentes com os dados obtidos por Cordeiro [14].

A CBC calcinada a temperatura de $500^{\circ} \mathrm{C}$, foi a que obteve menor índice de atividade pozolânica, sendo ainda abaixo do valor mínimo estabelecido que é de $330 \mathrm{mg} / \mathrm{g}$ para um material pozolânico, já os restantes das cinzas atendem este parâmetro, apresentando uma similaridade entre a temperatura de calcinação e o índice pozolânico [28].

\subsection{Difração de raio-X}

Através do ensaio de difração de raio-x, foi possível fazer a análise da mineralogia dos materiais, identificando as fazes cristalinas e amorfas das cinzas do bagaço da cana-de-açúcar. A Figura 07 apresenta os difratogramas das cinzas calcinadas em diferentes temperaturas.

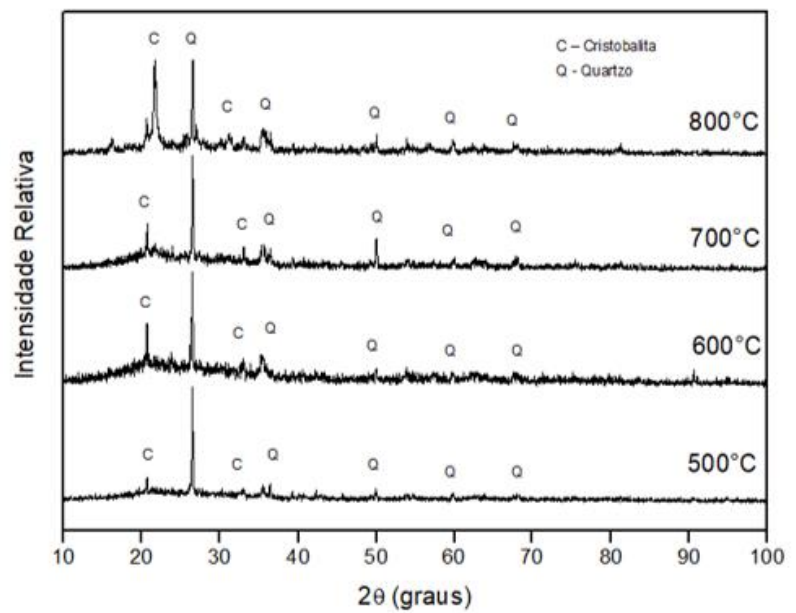

Figura 7: Difratogramas das cinzas de cana-de-açúcar. Autor (2020).

Ao analisar os difratogramas é possível verificar que ambas as cinzas apresentam picos elevados, situados no ângulo de $2 \Theta \sim 26^{\circ}$, estes picos são característicos do mineral quartzo (sílica cristalina), presente na composição das $\mathrm{CBC}$. Ainda a presença do quartzo na amostra pode ser explicada pela contaminação dela na hora da colheita pelo solo de origem.

Ainda na posição de $2 \Theta \sim 21^{\circ}$ é possível observar a presença de cristobalita em todas as temperaturas de calcinação, sendo que o grau de cristalinidade da cristobalita vai aumentando conforme a temperatura de calcinação se eleva, conforme demonstra os aumentos da intensidade dos picos nesta posição [13].

Em análise aos difratogramas constata-se que a temperatura de calcinação dos resíduos de cana-deaçúcar que resultou no material mais amorfo foi a de temperatura de $500^{\circ} \mathrm{C}$, já a temperatura de $800^{\circ}$ de calcinação resultou na CBC mais cristalina. 
A partir dos dados obtidos dos ensaios de DRX e da reatividade pozolânica, opta-se para dar seguimento a pesquisa utilizando as cinzas calcinadas na temperatura de $500^{\circ} \mathrm{C}$ por ser a cinza que obteve maior grau de amorfismo e menor atividade pozolânica e a cinza calcinada na temperatura de $800^{\circ} \mathrm{C}$ por ser a cinza que obteve menor grau de amorfismo e maior atividade pozolânica.

\subsection{Microscopia eletrônica de varredura}

Através do ensaio de microscopia eletrônica de varredura (MEV), foi possível fazer a análise da morfologia dos resíduos da cana-de-açúcar calcinados em diferentes temperaturas. A Figura 08 apresenta as imagens de MEV em um aumento de 500 vezes das CBC's.

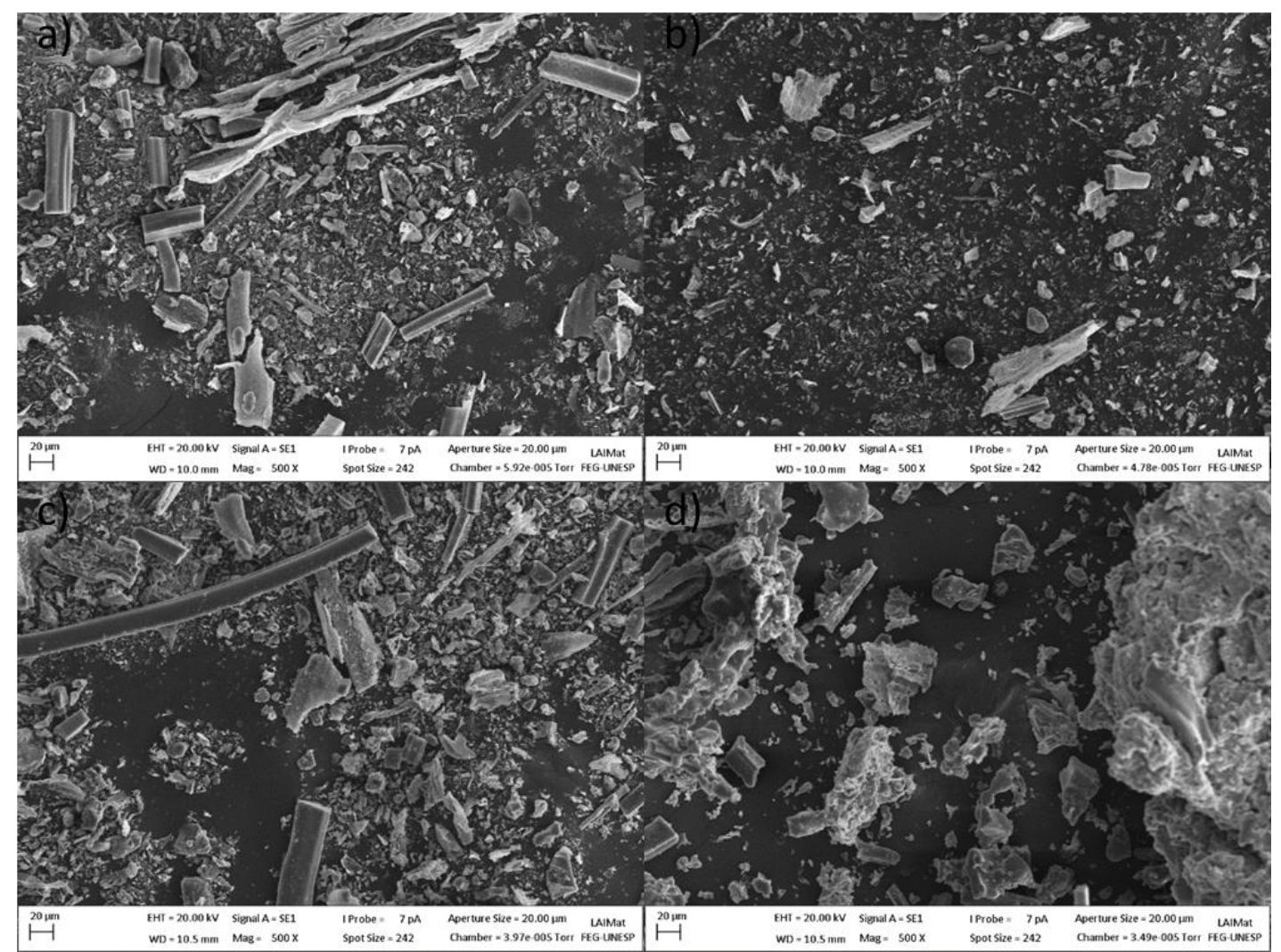

Figura 8: $\mathrm{MEV}$ das $\mathrm{CBC}$ sob aumento de 500 vezes onde $\mathrm{a}=500^{\circ} \mathrm{C}, \mathrm{b}=600^{\circ} \mathrm{C}, \mathrm{c}=700^{\circ} \mathrm{C}$ e $\mathrm{d}=800^{\circ} \mathrm{C}$. Autor (2020).

Ao analisar a Figura 08 é possível constatar que as CBC's possuem uma superfície áspera e de formato irregular, ainda é possível observar que as cinzas dos resíduos possuem uma superfície porosa [4]. Ainda a maior presença de partículas alongadas na amostra de $500^{\circ} \mathrm{C}$ expressa que o processo de calcinação não foi suficiente para a queima completa do bagaço de cana-de-açúcar [18].

A afirmação supracitada, corrobora com os dados obtidos na análise termogravimétrica (TGA), no qual a $\mathrm{CBC}$ calcinada na temperatura de $500^{\circ} \mathrm{C}$ obteve maior perda de massa, visto que o bagaço da cana-deaçúcar nesta temperatura não sofreu a queima completa.

A Figura 09 apresenta os MEV's realizados nas CBC's com aumento de 5000 vezes. Nela é possível observar pequenos impurezas (quartzo) que estão indicados nas imagens, confirmando os resultados obtidos no ensaio de DRX (Figura 07). Ainda se constata que as CBC possuem uma granulometria extremamente fina, ao ponto de em alguns pontos aglomerarem-se, este resultado condiz com os resultados observados por Fernandes Filho [18]. 


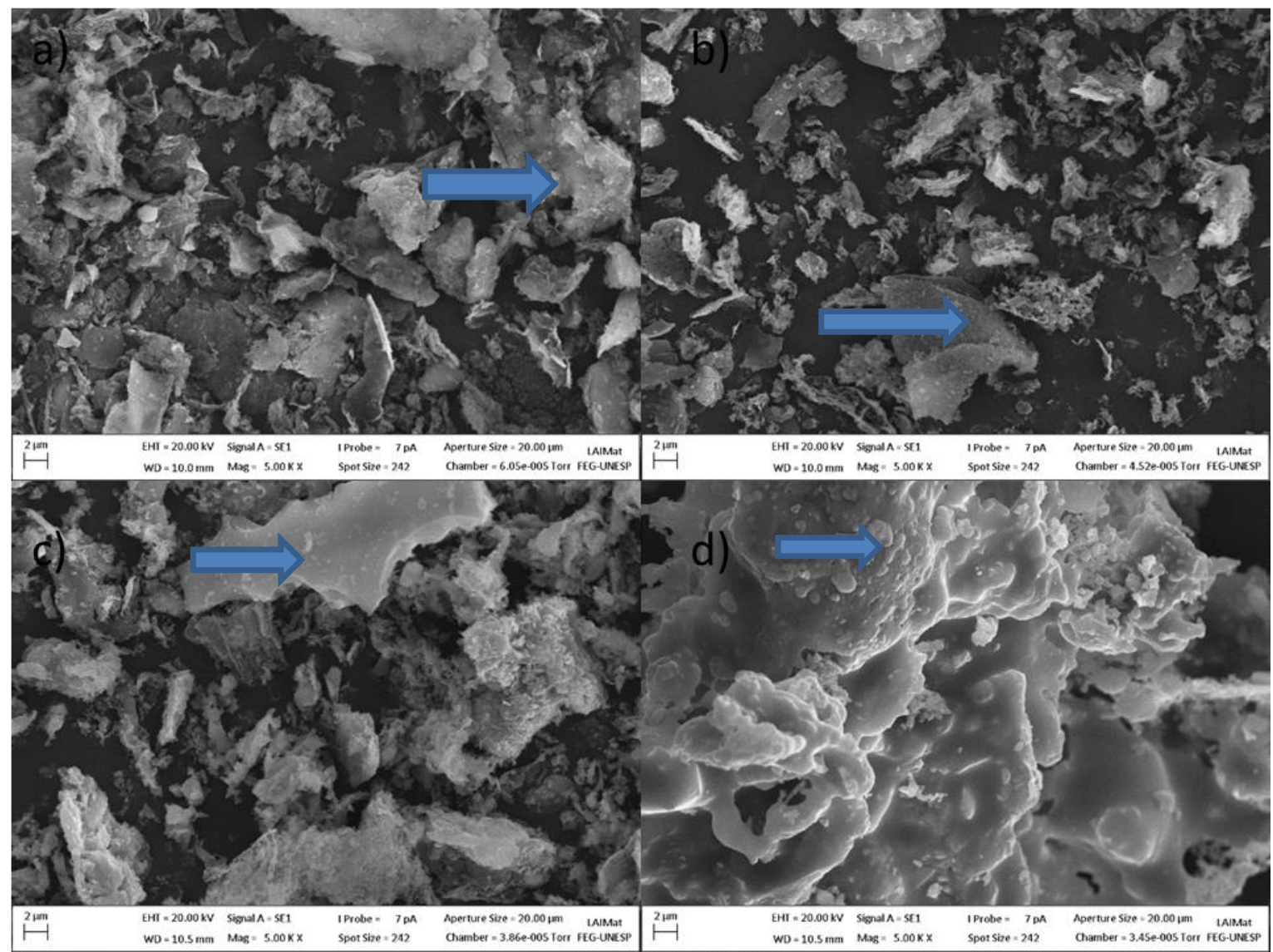

Figura 9: $\mathrm{MEV}$ das $\mathrm{CBC}$ sob aumento de 5000 vezes onde $\mathrm{a}=500^{\circ} \mathrm{C}, \mathrm{b}=600^{\circ} \mathrm{C}, \mathrm{c}=700^{\circ} \mathrm{C}$ e $\mathrm{d}=800^{\circ} \mathrm{C}$. Autor $(2020)$.

Na Figura 10, é possível observar que a calcinação dos resíduos de cana-de-açúcar ocasionou uma fratura nas fibrilas (parte da celulose) das CBC's, em alguns pontos conforme estão apontados, percebendo que quando maior a temperatura de calcinação maior será a fratura das fibrilas. Contudo ressalta-se que nem todas as fibrilas sofreram fraturas, pois o sistema da CBC é um sistema muito heterogêneo.

Na Figura 11 são apresentados os MEV's sob aumento de 20000 vezes, neles é possível observar que com as fraturas das fibrilas os componentes não cristalinos começaram a sair da amostra, conforme o grau de fratura da fibrila (quanto maior a fratura, maior a saída de componentes não cristalino). Esses componentes não cristalinos que saíram das fibrilas ficaram depositados na superfície do material e devido a elevada temperatura de calcinação se aglomeraram com o restante do resíduo, provocando uma mudança significativa na superfície e morfologia das CBC's. 


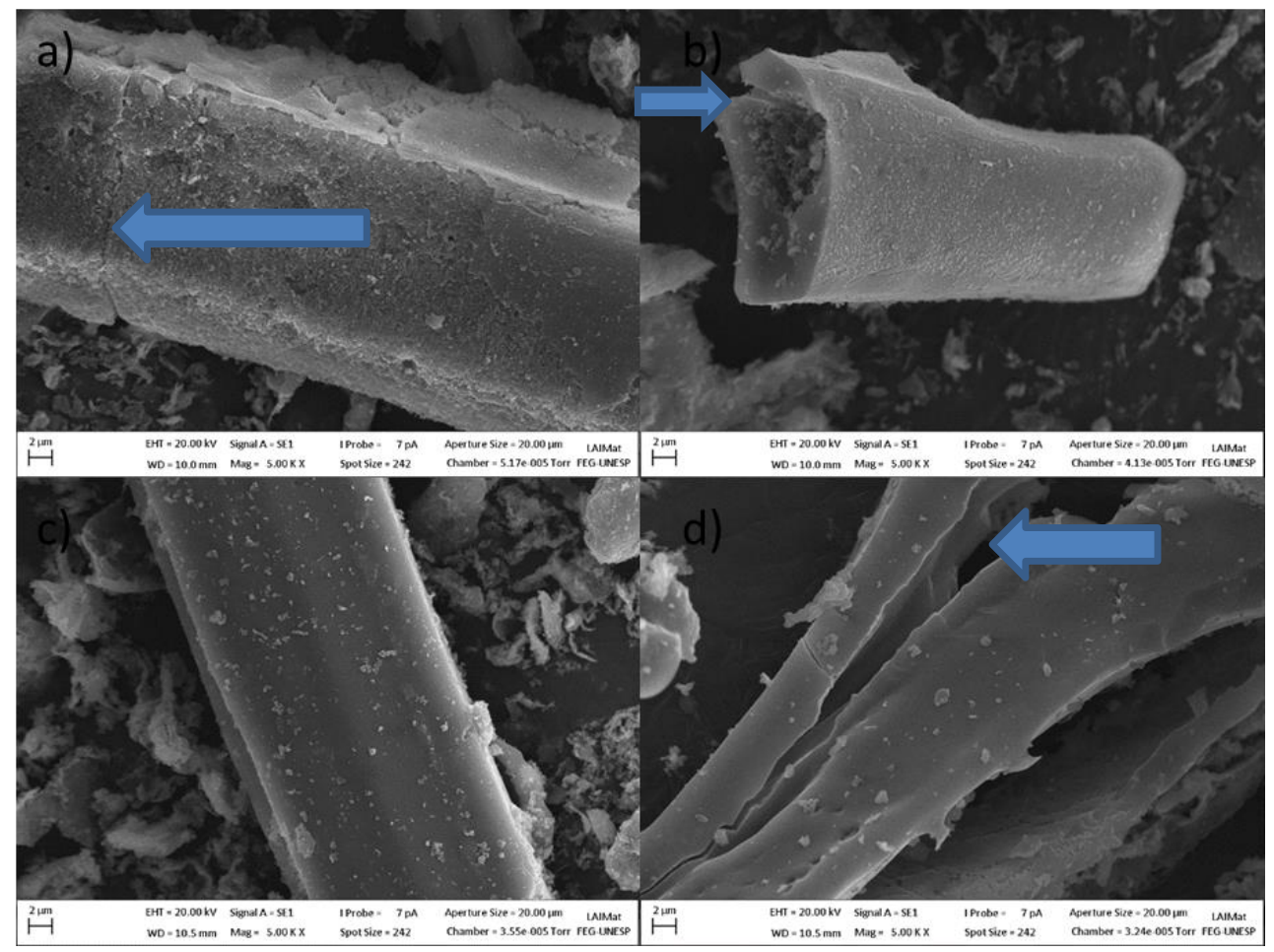

Figura 10: $\mathrm{MEV}$ das $\mathrm{CBC}$ sob aumento de 5000 vezes fibrila onde $\mathrm{a}=500^{\circ} \mathrm{C}, \mathrm{b}=600^{\circ} \mathrm{C}, \mathrm{c}=700^{\circ} \mathrm{C}$ e $\mathrm{d}=800^{\circ} \mathrm{C}$. Autor (2020).

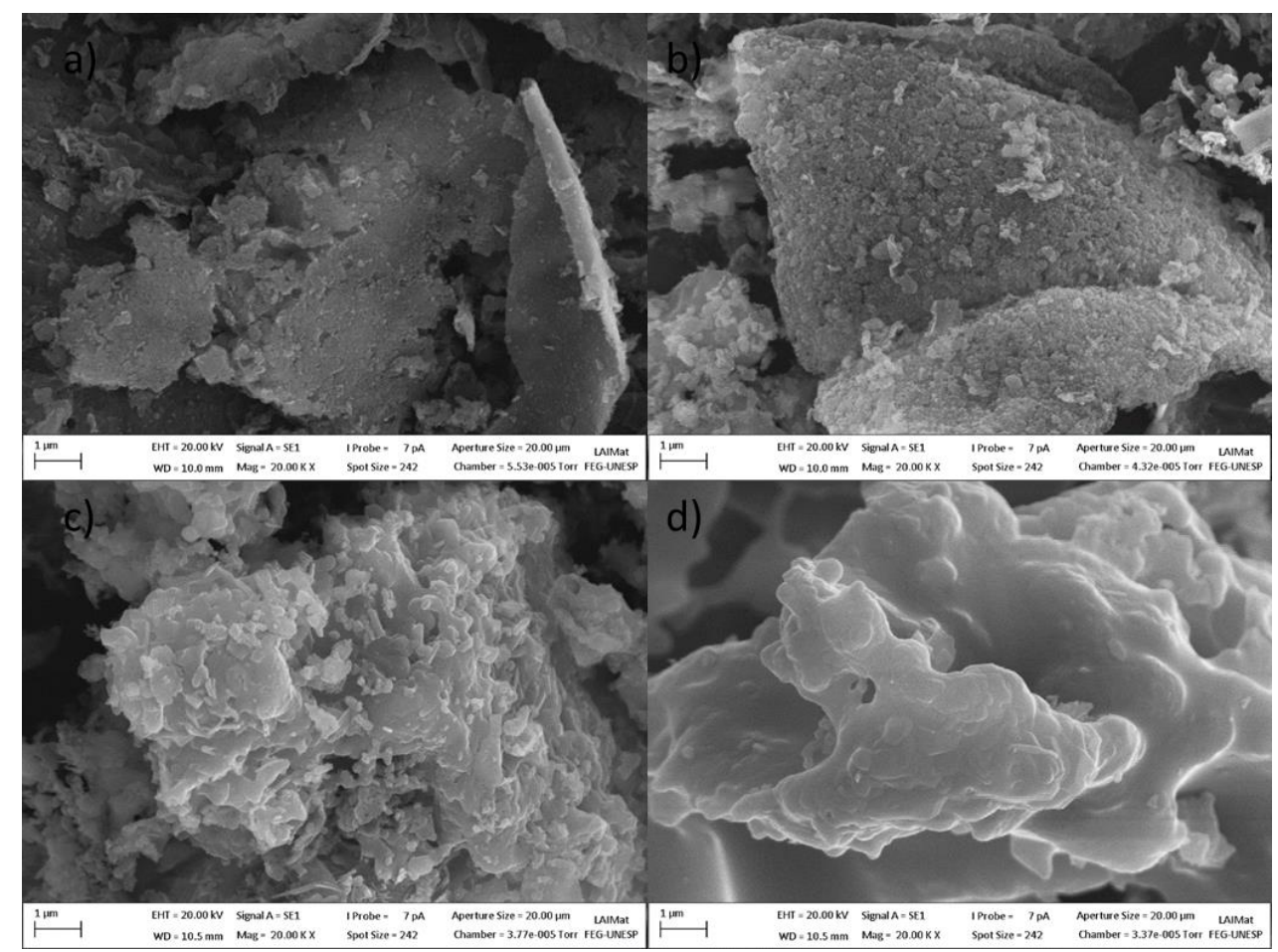

Figura 11: $\mathrm{MEV}$ das $\mathrm{CBC}$ sob aumento de 20000 vezes onde $\mathrm{a}=500^{\circ} \mathrm{C}, \mathrm{b}=600^{\circ} \mathrm{C}, \mathrm{c}=700^{\circ} \mathrm{C}$ e $\mathrm{d}=800^{\circ} \mathrm{C}$. Autor (2020). 


\section{CONCLUSÕES}

Buscando analisar a influência térmica da calcinação nas temperaturas de $500^{\circ} \mathrm{C}, 600^{\circ} \mathrm{C}, 700^{\circ} \mathrm{C}$ e $800^{\circ} \mathrm{C}$ para os resíduos da cana-de-açúcar, esse estudo traz resultados onde pode-se obter as seguintes conclusões:

Conforme a temperatura de calcinação dos resíduos foi aumentando, houve uma menor perda de massa da amostra calcinada, no qual percebeu-se que a partir de $700^{\circ} \mathrm{C}$ de calcinação durante um período de temperatura constante de 1 hora, a amostra passa a sofrer o processo inverso, em vez de perder massa, a mesma tem um aumento de massa. Isso ocorre em virtude de que após a temperatura de $600^{\circ} \mathrm{C}$ há a remoção de todo o carbono que recobria as amostras, ficando assim somente os óxidos nas amostras, que após a temperatura de $700^{\circ} \mathrm{C}$ começa-se a oxidar.

Quanto mais elevada for a temperatura de calcinação, maior é o índice de atividade pozolânica, tendo as amostras de $600^{\circ} \mathrm{C}, 700^{\circ} \mathrm{C}$ e $800^{\circ} \mathrm{C}$ superando o valor mínimo estipulado por Raverdy et al. (1980).

No DRX as amostras trazem o quartzo como principal material cristalino presente na composição seguido pela cristobalita. A principal origem do quartzo vem da contaminação do solo na hora da colheita da cana, e a cristobalita pela cristalização da sílica, que tende a crescer conforme a temperatura da calcinação aumenta.

Concluímos que a amostra de $500^{\circ} \mathrm{C}$ como a de maior amorfismo e a de $800^{\circ} \mathrm{C}$ como a de maior cristalinidade.

A calcinação faz com que ocorra fratura nas fibrilas (parte da celulose) das $\mathrm{CBC}$ 's, e que quanto maior a temperatura de calcinação, maiores e com mais frequências essas fraturas tendem a ser apresentadas.

No rompimento da fibrila, o seu interior não cristalino tende a sair da estrutura e se envolver com a superfície, que se aglomera com o restante do resíduo gerando uma mudança morfológica das CBC's.

Este estudo realizou a reciclagem do resíduo da cana-de-açúcar, apresentando ótimas características para um possível uso na construção civil, se mostrando de grande importância para a recuperação e reutilização de resíduos gerados pela agroindústria e promovendo um uso ambientalmente sustentável.

\section{AGRADECIMENTO}

Os autores agradecem o suporte prestado pela IMED e a disposição dos seus laboratórios para realização das atividades, a cooperativa dos produtores de cana-de-açúcar de Porto Xavier - Coopercana pelo fornecimento do resíduo da cana utilizada para o referente estudo, e o apoio financeiro provido pelas bolsas da CAPES e FAPERGS (19/2551-0000864-3).

\section{BIBLIOGRAFIA}

[1] Associação Brasileira de Normas Técnicas. NBR 10004. Resíduos sólidos - Classificação. Segunda edição. 31.05.2004. Rio de Janeiro: ABNT, 2004.

[2] Associação Brasileira de Normas Técnicas. Materiais Pozolânicos- Especificação. NBR 12653:2012. Rio de Janeiro: ABNT, 2012. Disponível em: <https://www.abntcatalogo.com.br/norma.aspx?ID=400221 >. Acesso em: 17 nov. 2019.

[3] Associação Brasileira de Normas Técnicas. NBR 15895. Determinação do teor de hidróxido de cálcio fixado pelo método de chapelle modificado. Rio de Janeiro: ABNT, 2010.

[4] APOLONIO, P.H. Produção de geopolímeros usando cinza de casca de arroz como fonte complementar de sílica. 2017. 98 f. Dissertação (Mestrado) - Curso de Engenharia Civil, Universidade Federal de Pernambuco, Caruaru, 2017.

[5]BEZERRA, A.C.S., SARAIVA, S.L.C., LARA, L.F.S., et al., Effect of partial replacement with thermally processed sugar cane bagasse on the properties of mortars. DOI 10.1590/S1517-707620170001.0117. Available at: https://revistas.ufrj.br/index.php/rm/article/view/13696. Accessed on: 24 Mar. 2021. Revista Materia, v. 22, n. 1, 13 Nov. 2017.

[6] BIGNO, I.C. Geopolímeros à base de resíduos agrícolas e agroindustriais. Instituto Militar de Engenharia, Rio de Janeiro, 2008.

[7] BRASIL, GOVERNO FEDERAL. (Org.). Plano Nacional de Resíduos Sólidos. Versão preliminar para consulta. Brasília, 2011. 102 p.

[8] BRASIL. SENADO FEDERAL. Conferência Rio-92 sobre o meio ambiente do planeta: desenvolvimento sustentável dos países. Disponível em: <https://www.senado.gov.br/noticias/Jornal/emdiscussao/rio20/ario20/conferencia rio-92-sobre-o-meio-ambiente-do-planeta-desenvolvimento-sustentavel-dos paises.aspx > . Acesso em: 18 jun. 2019. 
[9] BRASIL. GOVERNO FEDERAL. (Org.). Sobre a Rio+20. Disponível em: <http://www.rio20.gov.br/sobre_a_rio_mais_20.html . Acesso em: 18 jun. 2019.

[10] CASTALDELLI, V.N. Estudo de geopolímeros utilizando cinzas residuais do bagaço de cana-de-açúcar. 2013. 89f. Dissertação (Mestrado) - Curso de Engenharia Civil, Faculdade de Engenharia de Ilha Solteira, Ilha Solteira, 2013. Disponível em: 〈https://repositorio.unesp.br/handle/11449/111146〉. Acesso em: 28 jun. 2019.

[11] CIMENTO. ORG (Brasília). O Mundo do CIMENTO em 2016 e as perspectivas para 2017. 2017. Disponível em: <https://cimento.org/o-mundo-do-cimento-2016-e-2017/>. Acesso em: 10 jun. 2019.

[12] CIOFFI, R., MAFFUCCI, L., SANTORO, L. Optimization of geopolymer synthesis by calcination and polycondensation of a kaolinitic residue. Elsevier BV. http://dx.doi.org/10.1016/s0921-3449(03)00023-5. Resources, Conservation And Recycling, [s.1.], v. 40, n. 1, p.27-38, dez. 2003.

[13] CORDEIRO, G.C. Utilização de Cinzas Ultrafinas do Bagaço de Cana-de-Açúcar e da Casca de Arroz como Aditivos Minerais em Concreto. 2006. 485 f. Tese (Doutorado) - Curso de Engenharia Civil, Universidade Federal do Rio de Janeiro, Coppe, Rio de Janeiro, 2006.

[14] CORDEIRO, G.C., TOLEDO FILHO, R.D., FAIRBAIRN, E.M.R. Caracterização de cinza do bagaço de cana-de-açúcar para emprego como pozolana em materiais cimentícios. FapUNIFESP (SciELO). http://dx.doi.org/10.1590/s0100-40422009000100016. Química Nova, [s.l.], v. 32, n. 1, p.82-86, 2009.

[15] DAVIDOVITS, J. Years of successes and failures in geopolymer applications. Market trends and potential breakthroughs. In: GEOPOLYMER 2002 CONFERENCE 2002, Anais... : Geopolymer Institute Saint-quentin (France), Melbourne (Australia), 2002.

[16] DUXSON, P., FERNÁNDEZ-JIMÉNEZ, A., PROVIS, J.L. et al. Geopolymer techology: The current state of the art. Jornal of Materials Science, v. 42, n.9, p. 2917-2933, 2007.

[17] FAO - Organização das Nações Unidas para a Agricultura e Alimentação. Statistics. Disponível em: http://www.fao.org/statistics/en/. Acesso em: 14 maio de 2019.

[18] FERNANDES-FILHO, P. Utilização da cinza residual do bagaço de cana-de-açúcar na produção de materiais cimentícios alcalinamente ativados. 2012. 218 f. Tese (Doutorado) - Curso de Engenharia Mecânica, Universidade Federal da Paraíba, João Pessoa, 2012. Disponível em: <https://repositorio.ufpb.br/jspui/handle/123456789/13980>. Acesso em: 28 jun. 2019.

[19] FERNANDES, S.E., TASHIMA, M.M., DE MORAES, J.C.B., et al.. Cinza de bagaço de cana-deaçúcar (CBC) como adição mineral em concretos para verificação de sua durabilidade. https://doi.org/10.1590/S1517-707620150004.0096. Revista Materia, v. 20, n. 4, p. 909-923, 2015.

[20] FIGUEIREDO, E.B., SCALA JUNIOR, N. Greenhouse gas balance due to the conversion of sugarcane areas from burned to green harvest in Brazil. Agriculture, Ecosystems and Environment, v.141, n.1/2, p.7785, 2011.

[21] FREITAS, E.G.A., RODRIGUES, E.H.V., ARAUJO, R.C.L., et al. Efeito da adição de cinzas de bagaço de cana de açúcar na resistência à compressão de argamassa normal. In: Congresso Brasileiro de Engenharia Agrícola. 1998. v. 27. p. 219-21.

[22] GOMES, K.C., CARVALHO, M., DINIZ, D.P., et al. Carbon emissions associated with two types of foundations: CP-II Portland cement-based composite vs. geopolymer concrete. DOI 10.1590/s1517707620190004.0850. Available at: https://revistas.ufrj.br/index.php/rm/article/view/32106. Accessed on: 24 Mar. 2021. Revista Materia, v. 24, n. 4, 2019.

[23] GUEDES, C.L.B., ADÃO, D.C., QUESSADA, T.P., et al. Avaliação de biocombustível derivado do bio-óleo obtido por pirólise rápida de biomassa lignocelulósica como aditivo para gasolina. Química Nova, v.33, n.4, p.781-786, 2010.

[24] IBGE - Instituto Brasileiro de Geografia e Estatística. A geografia da cana-de-açúcar. Disponível em:https://www.ibge.gov.br/geociencias/organizacao-doterritorio/analises-do territorio/18939-a-geografiadacanadeacucar.html?=\&t=oque-e. Acesso em: 13 de maio de 2019.

[25] MEHTA, P.K. Sustainable cements and concrete for the climate change era-a review. In: Proceedings of the Second International Conference on Sustainable Construction Materials and Technologies, Aneona, Italy. 2010. p. 28-30.

[26] PACHECO-TORGAL, F., ABDOULLAHNEJAD Z., CAMÕES A.F., et al. Durability of alkaliactivated binders: A clear advantage over Portland cement or an unproven issue?. Elsevier BV. Construction And Building Materials, v. 30, p.400-405, maio 2012. 
[27] PAULA, M.D. Potencial da cinza do bagaço da cana-de-açúcar como material de substituição parcial de cimento Portland. Revista Brasileira de Engenharia Agrícola e Ambiental, v 13, n.3, 2006.

[28] RAVERDY, M. et al. Appreciation of pozzolanic reacivity of minor components. Appreciation of pozzolanic reactivity of minor components. França.1980.

[29] ROTH, C.G., GARCIAS, C.M. Construção Civil e a Degradação Ambiental. . Disponível em: <http://www.spell.org.br/documentos/ver/2880/construcao-civil-e-a-degradacao-ambiental>. Acesso em: 22 jun. 2019. Desenvolvimento em Questão, Ijui, v. 7, n. 13, p.111-128, jun. 2009

[30] SCHNEIDER, C.F., SCHULZ, D.G., LIMA, P.R., et al. Formas de gestão e aplicação de resíduos da cana-de-açúcar visando redução de impactos ambientais. Revista Eletrônica Verde de Agroecologia e Desenvolvimento Sustentável, Edição especial, Mossoró- RN,2012. v.7, n.5, p.08-17.

[31] SILVA, F.B.F. Estudo da influência dos métodos de composição na preparação de nanopartículas de óxidos magnéticos de ferro por rota solvotérmica. 2013. 80 f. Dissertação (Mestrado) - Curso de Química, Universidade Federal de São Carlos, São Carlos, 2013.

[32] SILVA, M.B., MORAIS, A.S. Avaliação Energética do Bagaço de Cana em Diferentes Níveis de Umidade e Graus de Compactação. XXVIII Encontro Nacional de Engenharia de Produção. Rio de Janeiro, RJ, Brasil, 13 a 16 de outubro de 2008. Disponível em:

<http://www.abepro.org.br/biblioteca/enegep2008_TN_STP_077_543_11289.pdf >. Acesso em: 18 jun. 2019.

[33] SOARES, A.B., et al. Estudo da oxidação total do etanol usando óxidos tipo perovskita LaBO3 (B= Mn, Ni, Fe). Química Nova, [s.1.], v. 30, n. 5, p.1061-1066, out. 2007. FapUNIFESP (SciELO). http://dx.doi.org/10.1590/s0100-40422007000500002.

\section{ORCID}

Aline Zanchet

Rafaela Fontana Casanova

Mateus Arlindo da Cruz

Daiane Boscardin https://orcid.org/0000-0002-5525-0483

https://orcid.org/0000-0002-1949-1511

https://orcid.org/0000-0003-3612-1456

https://orcid.org/0000-0002-1745-1348 